\title{
Contributions in renewable energy systems: A perspective from the latest publications of FCSE
}

\author{
Xiaowen Zhu' ${ }^{1}$, Di Xu $(\bowtie)^{2}$, Jing-Kang Wang ${ }^{1}$ \\ 1 School of Chemical Engineering and Technology, Tianjin University, Tianjin 300350, China \\ 2 College of Chemistry and Chemical Engineering, Chongqing University of Science \& Technology, Chongqing 401331, China
}

(C) Higher Education Press and Springer-Verlag GmbH Germany, part of Springer Nature 2019

The Chinese Academy of Engineering (CAE) has been conducting Engineering Fronts Projects for three years since 2017, which aim of the future development directions of engineering science and technology. The potential Research Fronts topics were obtained by Clarivate Analytics, which based on the cocitation clustering method and clustered the top $10 \%$ highly cited papers in the Web of Science Core Collection. "Renewable Energy System" got voting No. 1 in this project in 2019 in the field group of Chemical, Metallurgical, and Materials Engineering [1]. Among all 190 papers on this topic there are 8 papers got more than 100 citations in the Web of Science Core Collection [2-9].

Renewable energy (RE) is generated from natural processes that are continuously replenished, which typically refers to energy resources like wind, solar, biomass, hydropower, geothermal, and ocean energy. Today, the integration of RE into energy and chemical industries is increasingly studied and practiced, becoming a new trend of research in chemical science and engineering. Chemical science and engineering play critical roles in the upgrading of the global economy and society by offering multiple energies and chemicals. However, enormous benefits contributed by the modern energy and chemical industries are accompanied by several major challenges including depletion of fossil fuels, environmental pollutions, and global warming $[10,11]$. Therefore, significant efforts have been made over the past decades in realizing more sustainable energy and chemical technologies and processes, which are characterized by introducing renewable energy resources to replace fossil fuels.

As a journal concerning the latest progress in sustainable technologies and green processing, Frontiers of Chemical Science and Engineering (FCSE) could provide readers with valuable information in the domain of renewable energy and chemical systems, including producing chemicals and energies for the resources utilization, as well as developing devices and materials for the energy storage (Fig. 1). In this regard, we present three categories for indicating the contributions of chemical science and engineering (published by FCSE) in renewable energy systems.

\section{Contributions of chemical science \& engineering in the bio-energy system}

Bio-energy, compared with other carbon-free renewable energy resources like solar and wind, has much more interactions with chemical science and engineering; since it can be employed to produce chemicals, fuels, heat, and electricity via multiple conversion pathways [12]. Therefore, several publications can be found in FCSE for using chemical or bio-chemical approaches to support the bio-energy generation. Taking biomass, even sewage sludge as feedstock, multiple chemicals, biogas, and bio-fuel could be produced by resorting to thermal processes. For instance, glucose, cellulose, xylan, and lignin can be converted into hydrogen-rich gas by using alkali-thermal gasification at moderate temperatures without catalyst, which offers a promising way for producing the biomassbased hydrogen [13]. An effort has been made by Mao et al. [14] that upgrades the pyrolysis of bio-fuel from corncobs via integrating a zeolite-coated cordierite honeycomb into a bubbling fluidized bed pyrolyzer. Biogas is always a research focus for linking the renewable energy and the chemical engineering among the published works

Received October 12, 2019

E-mail: dixu@cqust.edu.cn 


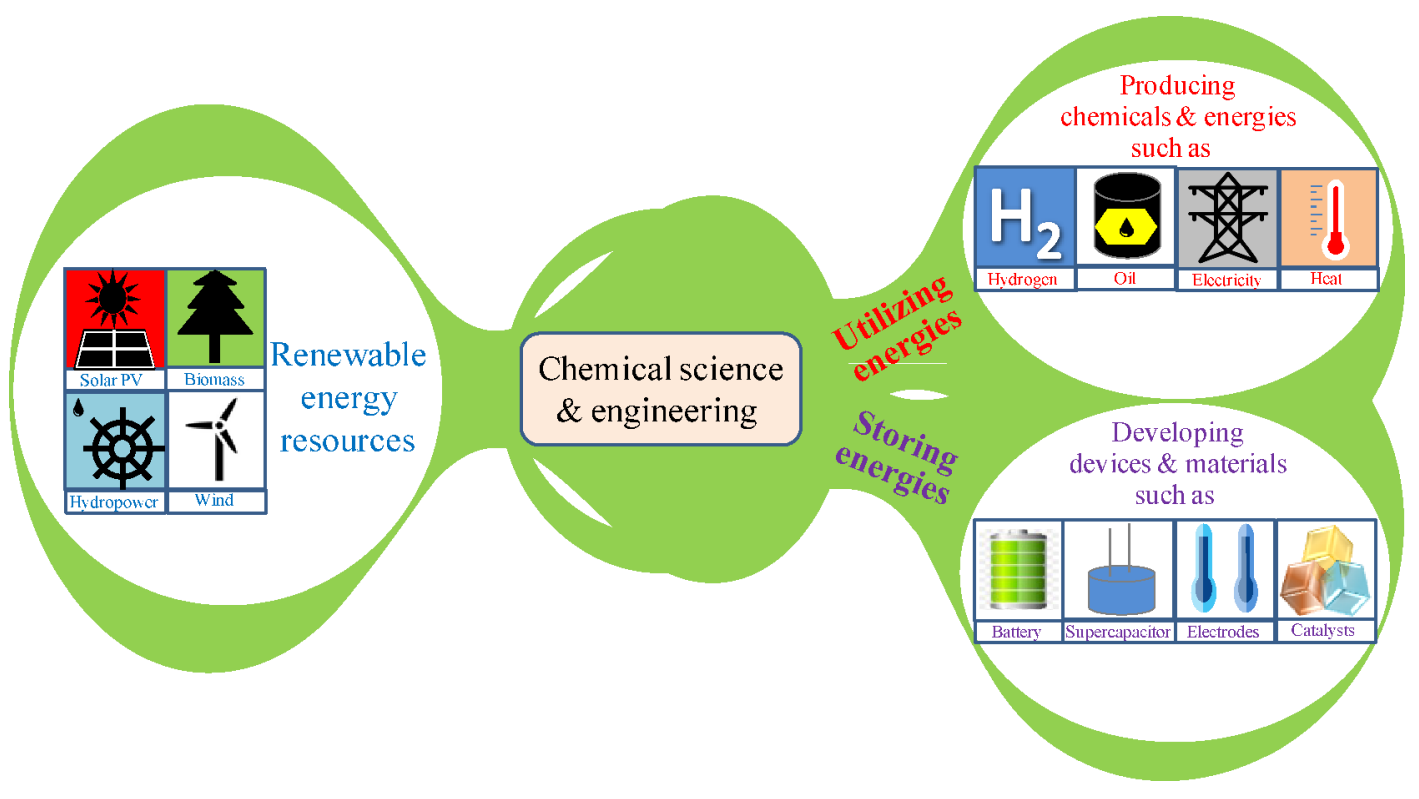

Fig. 1 An illustrative figure regarding the contributions of chemical science \& engineering in renewable energy systems.

in FCSE, i.e., a techno-economic assessment was carried out for generating biogas-based ethylene via oxidative coupling with methane [15]; the technical and economic feasibility of bio-methane plant with combined heat and power units was verified by Saracevic et al. [16]; while the possibility of using stabilized sewage sludge to produce methane-based biogas was also discussed [17]. Besides, biomass fermentation has been regarded as a promising way for the bio-energy production, such as ethanol from the fermentation of corn stover [18], and hydrogen from the dark fermentation of raw cassava starch [18]. New materials have also been developed for upgrading biomass conversion, for instance, carbide catalysts (especially $\mathrm{Mo}_{2} \mathrm{C} / \mathrm{y}-\mathrm{Al}_{2} \mathrm{O}_{3}$ ) are verified as promising substitutes (for noble metals) to support the hydro-pyrolysis of biomass [19]; while mesoporous zeolite catalysts would be beneficial to the bio-fuel upgrading and glycerol conversion [20].

\section{Contributions of chemical science \& engineering in the solar energy system}

As the most abundant form of energy resource on earth, solar energy would be a better option than bio-energy to be used for the generation of carbon-free chemicals, heat, and electricity [21]. Among the solar energy-related publications of FCSE, employing the electricity captured from sunlight for the water splitting is always a hotspot. Recently, Zhang et al. [22] reviewed the literature regarding the self-supported transition metal phosphides (TMP) electrodes for the hydrogen production via water splitting, where three types of TMP including catalysts growing on carbon-based substrates, catalysts growing on metal-based substrates, and free-standing catalyst films were comprehensively analyzed. Xie et al. [23] summarized the design and fabrication of layered double hydroxide electrocatalysts (for water splitting) that combined with core-shell nanoarrays. Wang and Zhang [24] presented the recent progress in the transition metal-based nanostructure materials for enhancing the electrochemical water splitting. Cui et al. [25] prepared $\mathrm{N}$-doped spherical aggregates of $\mathrm{TiO}_{2}$ nanosheet for giving a high conversion efficiency for solar energy in dye-sensitized solar cells. By viewing the concentrated solar power (CSP) as a promising system for the utilization of the sun's energy, Ding et al. [26] summarized and compared several molten chlorides that could be used as high-temperature thermal energy storage and heat transfer fluid materials in the CSP system. Besides, solar thermochemical processes were regarded as competitive alternatives that may replace fossil fuel-based ones, while an efficient design of solar receivers/reactors was offered by Uddin et al. [27] for improving the capacity of green fuels by integrating the solar energy.

\section{Contributions of chemical science \& engineering in the energy storage system}

For integrating intermittent energy sources like solar and wind power into energy and chemical systems, batteries 
and electrochemical storage devices are required [28]. Therefore, developing advanced energy storage systems to enhance the connection between renewable energy and chemical engineering is of great importance in FCSE. For instance, the above-mentioned water splitting technology is well-accepted as a promising way of storing solar energy. Besides, reversible solid oxide cells (RSOC) would be a solution for the massive storage of renewable energy, while a detailed model was built by Er-rbib et al. [29] for confirming the satisfactory performance of the RSOC-based Power-to-Gas process. Taking lithium-ion batteries (LIB) as a key technology in energy storage, Zhang and Paillard [30] reviewed some alternative electrolytes in LIB with the characteristic of high voltage and ethylene carbonate-free, demonstrating that several electrolytes would be preferred to be adopted in LIB. Among the publications of FCSE, more researches aim at exploiting new materials or upgrading existing ones for enhancing efficiencies of the electrical energy storage devices. For instance, nickel nanopore arrays acting as nanostructured current collectors, were utilized for developing ultrahigh rate solid-state supercapacitors [31]; porous polymer with sulfur and nitrogen doping features were tested in several electrochemical measurements including supercapacitor, electrocatalyzed ORR (oxygen reduction reaction), and $\mathrm{Zn}$-air batteries, implying that such polymer would be beneficial to electrochemical energy storage and conversion [32]; while a mini-review given by Zhao et al. [33] was conducted regarding the functional nanostructure with perfectly-ordered anodic aluminum oxide template, demonstrating that they could be functional materials in energy conversion and storage devices like photoelectrochemical, sodium-ion batteries, and supercapacitors.

This work gathers the FCSE papers with diversity contributions in renewable energy systems (by highlighting the bio-energy, solar energy, and energy storage), which demonstrates that chemical science and engineering should play significant roles in the realization of sustainable development goals for the whole society, via evolving into the context of renewable energy resources. As can be observed from the publications of FCSE, bio-energy may represent an opportunity for providing green chemical products as well as commodity energy; solar energy could offer renewable-based heat and electricity with minimum pollution to the environment; while electrical energy storage systems would act as a bridge for better integrating the renewable energy resources with chemical science and engineering. In general, this is the time for the chemical industry to re-image itself as a champion and driver of sustainable development by cooperating with renewable energy systems, while many global crises like global warming and pollutions, as well as fossil fuel depletion, would be averted or mitigated automatically.

\section{References}

1. Center of Strategic Studies, Chinese Academy of Engineering. Engineering Fronts 2019. Beijing: Higher Education Press, 2019, 61-62

2. Sperling K, Hvelplund F K, Mathiesen B V, Lund H, Connolly D, Wenzel H, Ostergaard P A. Smart Energy Systems for coherent 100\% renewable energy and transport solutions. Applied Energy, 2015, 145: 139-154

3. Budischak C, Sewell D, Thomson H, Mach L, Veron D E, Kempton W. Cost-minimized combinations of wind power, solar power and electrochemical storage, powering the grid up to $99.9 \%$ of the time. Journal of Power Sources, 2013, 225: 60-74

4. Pfenninger S, Hawkes A, Keirstead J. Energy systems modeling for twenty-first century energy challenges. Renewable \& Sustainable Energy Reviews, 2014, 33: 74-86

5. Noack J, Roznyatovskaya N, Herr T, Fischer P. The chemistry of redox-flow batteries. Angewandte Chemie International Edition, 2014, 54(34): 9775-9808

6. Huber M, Dimkova D, Hamacher T. Integration of wind and solar power in Europe: Assessment of flexibility requirements. Energy, 2014, 69: 236-246

7. Sharafi M, ELMekkawy T Y. Multi-objective optimal design of hybrid renewable energy systems using PSO-simulation based approach. Renewable Energy, 2014, 68: 67-79

8. Connolly D, Lund H, Mathiesen B V. Energy Europe: The technical and economic impact of one potential $100 \%$ renewable energy scenario for the European Union. Renewable \& Sustainable Energy Reviews, 2016, 60: 1634-1653

9. Elliston B, MacGill L, Diesendorf M. Least cost 100\% renewable electricity scenarios in the Australian National Electricity Market. Energy Policy, 2013, 59: 270-282

10. Arastoopour H. The critical contribution of chemical engineering to a pathway to sustainability. Chemical Engineering Science, 2019, 203: 247258

11. Xu D, Lv L, Ren J, Shen W, Wei S, Dong L. Life cycle sustainability assessment of chemical processes: A vector-based three-dimensional algorithm coupled with AHP. Industrial \& Engineering Chemistry Research, 2017, 56(39): 11216-11227

12. Celebi A D, Sharma H, Ensinas A V, Marechal F. Next generation cogeneration system for industry: Combined heat and fuel plant using biomass resources. Chemical Engineering Science, 2019, 204: 59-75

13. Koven A B, Tong S S, Farnood R R, Jia C Q. Alkali-thermal gasification and hydrogen generation potential of biomass. Frontiers of Chemical 
Science and Engineering, 2017, 11(3): 369-378

14. Mao L Y, Li Y X, Zhang C. Upgrading of derived pyrolysis vapors for the production of biofuels from corncobs. Frontiers of Chemical Science and Engineering, 2018, 12(1): 50-58

15. Penteado A T, Kim M, Godini H R, Esche E, Repke J U. Techno-economic evaluation of a biogas-based oxidative coupling of methane process for ethylene production. Frontiers of Chemical Science and Engineering, 2018, 12(4): 598-618

16. Saracevic E, Woess D, Theuretzbacher F, Friedl A, Miltner A. Techno-economic assessment of providing control energy reserves with a biogas plant. Frontiers of Chemical Science and Engineering, 2018, 12(4): 763-771

17. Turek V, Kilkovský B, Jegla Z, Stehlík P. Proposed EU legislation to force changes in sewage sludge disposal: A case study. Frontiers of Chemical Science and Engineering, 2018, 12(4): 660-669

18. Wang S J, Ma Z H, Zhang T, Bao M D, Su H J. Optimization and modeling of biohydrogen production by mixed bacterial cultures from raw cassava starch. Frontiers of Chemical Science and Engineering, 2017, 11(1): 100-106

19. He S B, Boom J, van der Gaast R, Seshan K. Hydro-pyrolysis of lignocellulosic biomass over alumina supported $\mathrm{Platinum} \mathrm{Mo}_{2} \mathrm{C}$ and $\mathrm{WC}$ catalysts. Frontiers of Chemical Science and Engineering, 2018, 12(1): 155-161

20. Zhang J, Wang L, Ji Y Y, Chen F, Xiao F S. Mesoporous zeolites for biofuel upgrading and glycerol conversion. Frontiers of Chemical Science and Engineering, 2018, 12(1): 132-144

21. Agrawal R, Mallapragada D S. Chemical engineering in a solar energy-driven sustainable future. AIChE Journal. American Institute of Chemical Engineers, 2010, 56(11): 2762-2768

22. Zhang Y, Xiao J, Lv Q Y, Wang S. Self-supported transition metal phosphide based electrodes as high-efficient water splitting cathodes. Frontiers of Chemical Science and Engineering, 2018, 12(3): 494-508

23. Xie W F, Li Z H, Shao M F, Wei M. Layered double hydroxide-based core-shell nanoarrays for efficient electrochemical water splitting. Frontiers of Chemical Science and Engineering, 2018, 12(3): 537-554

24. Wang Y, Zhang J. Structural engineering of transition metal-based nanostructured electrocatalysts for efficient water splitting. Frontiers of Chemical Science and Engineering, 2018, 12(4): 838-854

25. Cui Z J, Zhang K Y, Xing G Y, Feng Y Q, Meng S X. Multi-functional 3D N-doped $\mathrm{TiO}_{2}$ microspheres used as scattering layers for dyesensitized solar cells. Frontiers of Chemical Science and Engineering, 2017, 11(3): 395-404

26. Ding W J, Bonk A, Bauer T. Corrosion behavior of metallic alloys in molten chloride salts for thermal energy storage in concentrated solar power plants: A review. Frontiers of Chemical Science and Engineering, 2018, 12(3): 564-576

27. Uddin M H, Ozalp N, Heylen J, Ophoff C. A new approach for fuel injection into a solar receiver/reactor: Numerical and experimental investigation. Frontiers of Chemical Science and Engineering, 2018, 12(4): 683-696

28. Gür T M. Review of electrical energy storage technologies, materials and systems: Challenges and prospects for large-scale grid storage. Energy \& Environmental Science, 2018, 11(10): 2696-2767

29. Er-rbib H, Kezibri N, Bouallou C. Performance assessment of a power-to-gas process based on reversible solid oxide cell. Frontiers of Chemical Science and Engineering, 2018, 12(4): 697-707

30. Zhang T, Paillard E. Recent advances toward high voltage, EC-free electrolytes for graphite-based Li-ion battery. Frontiers of Chemical Science and Engineering, 2018, 12(3): 577-591

31. Zhao H P, Liu L, Fang Y G, Vellacheri R, Lei Y. Nickel nanopore arrays as promising current collectors for constructing solid-state supercapacitors with ultrahigh rate performance. Frontiers of Chemical Science and Engineering, 2018, 12(3): 339-345

32. Zhang C, Lu C B, Bi S, Hou Y, Zhang F, Cai M, He Y F, Paasch S, Feng X L, Brunner E, Zhuang X D. S-enriched porous polymer derived Ndoped porous carbons for electrochemical energy storage and conversion. Frontiers of Chemical Science and Engineering, 2018, 12(3): 346-357

33. Zhao H P, Liu L, Lei Y. A mini review: Functional nanostructuring with perfectly-ordered anodic aluminum oxide template for energy conversion and storage. Frontiers of Chemical Science and Engineering, 2018, 12(3): 481-493 